\title{
Impact of a maternal and newborn health results-based financing intervention (RBF4MNH) on stillbirth: a cross-sectional comparison in four districts in Malawi
}

Regina Makuluni ${ }^{1^{*}}$ (D) and William Stones ${ }^{2}$

\begin{abstract}
Background: Malawi implemented a Results Based Financing (RBF) model for Maternal and Newborn Health, "RBF4MNH" at public hospitals in four Districts, with the aim of improving health outcomes. We used this context to seek evidence for the impact of this intervention on rates of antepartum and intrapartum stillbirth, taking women's risk factors into account.

Methods: We used maternity unit delivery registers at hospitals in four districts of Malawi to obtain information about stillbirths. We purposively selected two districts hosting the RBF4MNH intervention and two non-intervention districts for comparison. Data were extracted from the maternity registers and used to develop logistic regression models for variables associated with fresh and macerated stillbirth.

Results: We identified 67 stillbirths among 2772 deliveries representing 24.1 per 1000 live births of which 52\% ( $n=$ 35) were fresh (intrapartum) stillbirths and $48 \%(n=32)$ were macerated (antepartum) losses. Adjusted odds ratios (aOR) for fresh and macerated stillbirth at RBF versus non-RBF sites were $2.67(95 \% \mathrm{Cl} 1.24$ to $5.57, P=0.01)$ and 7.27 $(95 \% \mathrm{Cl} 2.74$ to $19.25 P<0.001)$ respectively. Among the risk factors examined, gestational age at delivery was significantly associated with increased odds of stillbirth.

Conclusion: The study did not identify a positive impact of this RBF model on the risk of fresh or macerated stillbirth. Within the scientific limitations of this non-randomised study using routinely collected health service data, the findings point to a need for rigorously designed and tested interventions to strengthen service delivery with a focus on the elements needed to ensure quality of intrapartum care, in order to reduce the burden of stillbirths.
\end{abstract}

\section{Background}

The 2015 global estimate for stillbirths was 18.4 per 1000 live births, a $25.5 \%$ reduction from 24.7 in 2000 [1]. Expressed as absolute numbers this corresponded in 2015 to 2.6 million losses, representing a 19\% decline since 2000. However, the smallest reduction was documented in sub-Saharan Africa [1]. Until recently, deaths

\footnotetext{
* Correspondence: reg.mak55@gmail.com

${ }^{1}$ College of Medicine, The University of Malawi, Private Bag 360, Blantyre, Malawi

Full list of author information is available at the end of the article
}

of fetuses before and during labour have remained relatively invisible to policymakers, development partners and funding agencies, despite the commonalities between risk factors for stillbirth and those for neonatal mortality [2]. A global target for stillbirth has been set at 12 per 1000 live births by 2030 against the current 18.4 per 1000 live births [3]. Across all settings, poor quality health care is an important risk factor for stillbirth. Both lack of access to antenatal care and suboptimal quality of intrapartum obstetric care have been highlighted as increasing the risk of stillbirth [4]. 
While improved access to and quality of antenatal care may prevent instances of antepartum fetal loss through detection of conditions such as pre-eclampsia, improved obstetric care during labour and delivery has a major role to play in prevention of intrapartum (fresh) stillbirth [5]. Just under half of all stillbirths in low and middle income countries occur during labour and delivery [6]. By contrast, in high income countries these deaths largely occur before labour and the intrapartum fetal death of an apparently healthy fetus has become rare, suggesting that with optimal obstetric care, most of these stillbirths are preventable $[4,6]$. In Malawi, the overall stillbirth rate is estimated at 24 per 1000 births [3, 7].

As a programmatic response, the Government of Malawi through the Ministry of Health Reproductive Health Directorate (RHD) adopted an initiative in 2013 entitled "Results-Based Financing for Maternal and Newborn Health" (RBF4MNH) in four Districts, Dedza, Ntcheu, Mchinji and Balaka. The aim of the initiative was to improve the quality of maternal and newborn care services while maintaining high rates of service utilization in both public and selected private not-forprofit facilities [8]. The initiative included both supply and demand-side incentives with a supply-side intervention (Performance Based Financing, PBF) that comprised financial rewards to health facilities attaining pre-defined indicators of clinical and organizational performance in labour, delivery, and newborn care [9]. The financial allocation was to be utilised depending on the hospital's needs for investment in promoting quality maternal and newborn health care. A demand-side component was to facilitate access and was provided through cash transfers to pregnant women.

The programme had a strong focus on increased quality of maternal and neonatal health care, staff motivation, providing monetary support to pregnant women to reduce access gaps and extending community awareness of institutional deliveries. Stillbirth rate reduction was not specified as a performance indicator. The goal of RBF was to enable more women, particularly from poor rural areas, to deliver in health facilities, and for those facilities to offer better quality maternal and neonatal care services [10]. Typically, in Malawi a woman stays in hospital for a maximum of $24 \mathrm{~h}$ after normal delivery owing to space constraints while in RBF hospitals a stay of $48 \mathrm{~h}$ post-delivery was mandated [11]. Besides performance contracts, the RBF4MNH initiative also included an initial input component to address basic infrastructural needs and addressing of minor building repairs [10]. Separate sets of performance incentives were set up for the District Health Management Teams (DHMT) in each of the four districts.

Apart from receiving incentives, health workers underwent training and received mentorship in the provision of care to women and newborns. The intervention's impact on maternal and newborn health service utilization and quality of care has been reported [12]. Here, we undertook a comparison of intervention and nonintervention sites to assess the impact on stillbirth.

\section{Methods}

This was a quantitative cross-sectional study which used routinely collected hospital data in the referral hospitals serving the districts of Ntcheu, Dedza, Salima (Central region) and Thyolo (Southern region). These district hospitals provide a secondary level of care and serve as the referral hospitals for all the primary health centres in their respective districts. The RBF districts were purposively selected because of ready access to hospital records. The non-RBF comparison districts were randomly selected by applying a random number table to a list of Malawi districts. The primary outcome for analysis was stillbirth, defined as an infant born with no signs of life at or after 28 weeks gestation [13].

A power calculation to determine the sufficiency of the number of register records was performed using Open Epi version 3 resulting in a sample of 2800 with a power of $90 \%$, at a statistical significance level of $5 \%$. This was based on anticipated stillbirth rates of 15 per 1000 live births in the combined population of the intervention hospitals and 34 per 1000 in the combined population in the non-intervention hospitals. These assumptions were based on initial scrutiny of District Health Management Information System (DHIS-2) returns.

Data were extracted from the registers which are used in maternity units to prepare routine monthly reports. Data collected included maternal age, gravidity (number of pregnancies), and gestational age in weeks, preeclampsia, low birth weight and stillbirths. We used assessment of gestational age and birth weight recorded in the registers following the routine practice of health facilities. In Malawi, most women do not undergo sonography to confirm gestational age. In these hospitals, weighing of the newborns is done by the midwives using routinely available hospital weighing scales. A prepared data extraction tool in the form of a register was used. Data were entered into Microsoft Excel and checked for accuracy, consistency, and completeness. Analysis was undertaken using STATA version 14. For continuous variables, means and standard deviations were considered and presented. Logistic regression models were developed to determine the odds ratio for stillbirth under intervention and non-intervention conditions, and to assess whether the statistical relationship was confounded by other factors. The possible confounders included in the multivariable models were; low birth weight, 
gestational age, gravidity and a diagnosis of preeclampsia, based on findings in two previous local studies $[6,7]$.

The study was approved on a waiver of the need for individual participant consent by the nationally mandated College of Medicine Research and Ethics Committee (COMREC) and administrative permission for access was granted by the Hospital authorities.

\section{Results}

We obtained records of 2800 births, of which 28 (1\%) were discarded during data cleaning owing to incorrect and missing values. Of these, $0.6 \%(n=8)$ observations were dropped at RBF sites while $1.4 \%(n=20)$ observations were dropped in the non-RBF sites. A total of 2772 delivery records were used in the final analyses. One thousand three hundred ninety-two of the deliveries were from RBF sites representing $50.2 \%$ while 1380 were from non-RBF sites representing 49.8\%.

\section{Demographic characteristics of the mothers with stillbirths}

The mean maternal age was 24 years (SD: 6.66). Most of the women (43.3\%) were aged between 25 and 34 with $4.5 \%$ aged below 18 years. Just under half $(47.8 \%, n=32)$ were in their first or second pregnancy as shown in Table 1 below.

\section{Factors associated with stillbirth}

During the study period, 67 stillbirths were identified out of 2772 deliveries. Fifty-two percent $(n=35)$ were classified as fresh (intrapartum) stillbirths while 48\% $(n=32)$ were macerated (antepartum) stillbirths in the maternity unit registers. Regarding gestational age of the entire sample population, $16.7 \%(n=463)$ were preterm and $83.3 \%(n=2309)$ presented at term.

Table 1 Demographic characteristics of the mothers with stillbirths

\begin{tabular}{llll}
\hline Variable & & Frequency & Percentage \\
\hline Age (years) & Less than 18 & 3 & 4.5 \\
& 18 to 19 & 11 & 16.4 \\
& 20 to 24 & 18 & 26.9 \\
& 25 to 34 & 29 & 43.3 \\
& $35+$ & 6 & 8.9 \\
Number of pregnancies & 1 to 2 & 32 & 47.8 \\
Gestational age (Weeks) & $3+$ & 35 & 52.2 \\
& 28 to 33 & 12 & 17.9 \\
& 34 to 36 & 10 & 14.9 \\
& 37 to 39 & 41 & 61.3 \\
& 40 to 42 & 4 & 5.9 \\
& 43 above & 0 & 0 \\
\hline
\end{tabular}

There were 1340 live births at the RBF sites and 1365 live births at non-RBF sites representing 96.3 and $98.9 \%$ of all births respectively (Table 2). More stillbirths were observed in the RBF sites than non-RBF sites, 3.8 and $1.1 \%$ respectively $(P<0.001)$. Other bivariate associations noted were with gestational age: of the 441 preterm births, $22(4.7 \%)$ were stillbirths $(P<0.001)$ and low birth weight: of the 263 newborns with low birth weight, $4.7 \%$ were stillbirths $(P=0.01)$. Other potential associations were non-significant.

\section{RBF- result based finance}

Multivariate analysis was undertaken separately for stillbirths classified as fresh (Table 3) and macerated (Table 4). The odds of both types of stillbirth were increased at RBF relative to non-RBF sites after controlling for variables that were significant in bivariate analyses against RBF. These were preterm birth and low birth weight, resulting in an adjusted odds ratio (aOR) for fresh (intrapartum) losses of $2.67,95 \%$ CI 1.24 to 5.57 , $P=0.01$. Thus, considering gestational age, and low birth weight as possible confounders, RBF status appears to be adverse rather than protective against fresh stillbirth with an aOR of 2.67 .

Table 2 Factors associated with stillbirth, comparison between RBF and non-RBF sites

\begin{tabular}{|c|c|c|c|c|}
\hline Variable & Frequency & Live (\%) & Stillbirth (\%) & $P$ Value \\
\hline & & RBF & & \\
\hline Yes & 52 & 96.3 & 3.7 & $<0.001$ \\
\hline No & 15 & 98.9 & 1.1 & \\
\hline \multicolumn{5}{|l|}{ Age group } \\
\hline Below 18 & 3 & 98.8 & 1.2 & 0.108 \\
\hline 18-19 & 11 & 97.9 & 2.1 & \\
\hline $20-24$ & 18 & 97.9 & 2.1 & \\
\hline $25-34$ & 29 & 96.4 & 3.6 & \\
\hline $35+$ & 6 & 98.2 & 1.8 & \\
\hline Gravidity & & & & 0.256 \\
\hline Primigravida & 23 & 97.9 & 2.1 & \\
\hline $2-5$ & 36 & 97.5 & 2.5 & \\
\hline $6+$ & 8 & 96.6 & 3.4 & \\
\hline Gestation Age & & & & $<0.001$ \\
\hline Preterm & 22 & 95.3 & 4.7 & \\
\hline Term & 45 & 98.1 & 1.9 & \\
\hline Preeclampsia & & & & 0.528 \\
\hline Yes & 0 & 100 & 0.0 & \\
\hline No & 67 & 97.6 & 2.4 & \\
\hline Low birth weight & & & & 0.009 \\
\hline Yes & 13 & 95.3 & 4.7 & \\
\hline No & 54 & 97.8 & 2.2 & \\
\hline
\end{tabular}


Table 3 Fresh stillbirth: adjusted odds of associations with selected variables

\begin{tabular}{|c|c|c|c|c|}
\hline Variable & Category' Reference group & aOR & $95 \% \mathrm{Cl}$ & $P$ Value \\
\hline$\overline{\mathrm{RBF}}$ & $\begin{array}{l}\text { Yes }(n=25) \\
\text { No }(n=10)\end{array}$ & 2.67 & $1.24-5.57$ & 0.010 \\
\hline Gestation age & $\begin{array}{l}\text { Preterm }(n=8) \\
\text { Term }(n=27)\end{array}$ & 1.61 & $0.68-3.66$ & 0.29 \\
\hline Low birth weight & $\begin{array}{l}\text { Yes }(n=6) \\
\text { No(n-29) }\end{array}$ & 1.63 & $0.66-4.20$ & 0.26 \\
\hline
\end{tabular}

\section{Multiple logistic regression model of RBF and other factors associated with macerated stillbirths}

The odds of macerated stillbirth were 7-fold higher when a mother delivered at an RBF site $(\mathrm{aOR}=7.27) \mathrm{CI}$ : 2.74 to $19.25, P<0.001)$. An association between gestational age and macerated stillbirth was significant (aOR 5.11 CI: 2.20-10.07, $P<0.001)$. Thus, adjusting for prematurity slightly increased the apparent adverse association with delivery at an RBF site (Table 4) andas for fresh stillbirth risk, RBF status appears adverse and not to be a factor protective against the risk of macerated stillbirth.

\section{Discussion}

We identified 67 stillbirths out of the 2772 births analyzed from the four hospital registers representing 24/ 1000 live births, a burden of mortality that is closely comparable to the current national estimate [3, 14]. The stillbirth rate identified at RBF sites was 37/1000 live births, substantially higher than at the non-RBF sites which recorded 10/1000 live births.

Intrapartum (fresh) stillbirth is considered to be a measure of the quality of intrapartum care or may reflect inadequacies in antenatal care such that those developing complications are not identified in a timely manner. In our study, stillbirth was significantly more common in RBF sites compared to non-RBF sites: this represents an unintended effect of the financing intervention. In a previous report drawing on experience from Malawi that explored intended and unintended effects of performance-based financing, it was found that apart from a positive impact of PBF on service delivery, unintended effects may occur owing to implementation realities. These include health system factors such as inadequate human resources to cater for the increased service load induced by the intervention [15]. The observed increase in the number of stillbirths at RBF sites could also have resulted from improved documentation and record keeping. This was emphasised in the RBF4MNH program implementation and of course absent at non RBF sites. As an indication that quality of record keeping may indeed partly explain our findings, it was more difficult to locate maternity registers at the non-RBF sites during data collection.

The approximately equal proportions of fresh and macerated stillbirth observed here is consistent with other reports from southern Africa where half or more of the losses were intrapartum [16]. In Gambia, similar findings were attributed to the non-use of the partograph and obstetric complications during intrapartum period [17]. In an evaluation of RBF4MNH impact in Malawi, there was no effect observed on the clinical performance of labor monitoring and partograph documentation with around half of women monitored with complete partographs [8]. This observation is consistent with our findings and may serve to discount the possibility that the apparent adverse effect of the intervention could be entirely a result of improved record keeping.

Previous systematic reviews have found that the most common factors associated with stillbirth in low resource countries were the lack of adequate antenatal care, lack of a skilled attendant at delivery, low socioeconomic status, poor nutrition, previous stillbirths and advanced maternal age [18-20]. In the RBF4MNH evaluation study, utilization rates for other maternal care services, specifically timely first antenatal care and at least 4 antenatal care visits, was found to stagnate at very low levels [8]. In Nigeria, over half (57.0\%) of the mothers with stillbirths had no antenatal care [21]. Although evidence supporting a direct and linear

Table 4 Macerated stillbirth: adjusted odds of associations with selected variables

\begin{tabular}{|c|c|c|c|c|}
\hline Variable & Category' Reference group & aOR & $95 \% \mathrm{Cl}$ & $P$ Value \\
\hline$\overline{\mathrm{RBF}}$ & $\begin{array}{l}\text { Yes }(n=27) \\
\text { No(n=5) }\end{array}$ & 7.27 & $2.74-19.25$ & $<0.001$ \\
\hline Gestation age & $\begin{array}{l}\text { Preterm }(n=14) \\
\operatorname{Term}(n=18)\end{array}$ & 5.11 & $2.20-10.07$ & $<0.001$ \\
\hline Low birth weight & $\begin{array}{l}\text { Yes }(n=7) \\
\text { No }(=25)\end{array}$ & 1.58 & $0.65-3.99$ & 0.312 \\
\hline
\end{tabular}


relationship between antenatal care and stillbirth is lacking, some of the apparent adverse effect of RBF4MNH could also be attributed to low antenatal care utilization as reported in the RBF4MNH final results, even noting the higher overall uptake of antenatal care in Malawi than some other regional countries [8]. Antenatal care can potentially serve as a platform to deliver interventions to improve the quality maternal care and early detection of risk factors that may lead to stillbirths [22]. Several factors beyond those explored in this study could also have contributed to the increase in the number of stillbirths in the RBF4MNH facilities. These factors include increase in service utilization due to incentives given leading to pressure of work, hence affecting quality of care given to the mother during labour and delivery [8].

In this study, a majority of the stillbirths were recorded in the mothers aged between 25 to 34 years with the least being recorded in adolescents below the age of 18. Although age did not show any statistical significance and trends, other subgroups have potentially programmatic significance. For example, a study conducted in Ghana reported that the lifetime risk of stillbirth was $40 \%$ higher among adolescents as compared to older mothers [23]. Similarly, a multicountry study conducted to describe the pregnancy outcomes among adolescent mothers reported that a high risk of stillbirth was found among all adolescent age groups, but the risk was significant only among adolescent mothers aged $16-17$ years [24]. However, the finding of no association of stillbirths with age observed in this study is likely to reflect the small numbers in this group and should not detract from messages that adolescent reproductive health should remain a priority for both national governments and the global health community.

Preterm birth was significantly associated with stillbirth (33\%) and this was observed at both RBF and non-RBF sites. A referral hospital-based study in Malawi also identified preterm birth as a factor associated with stillbirth, and recorded $67 \%$ of stillbirths who were preterm (Chilinda GK. Aetiology of stillbirths and adverse newborn outcomes at Queen Elizabeth Central Hospital, Blantyre, Malawi. [Dissertation] Zomba: University of Malawi; 2017 [Unpublished]). The variations in the reported percentages could be due to the difference in study design and the setting, but overall the link between stillbirth risk and preterm birth is an established one [25]. Thus, increasing attention to interventions to prevent preterm birth and stillbirth, alongside increasing investment for the health and wellbeing of mothers, will accelerate progress for these maternal, fetal, and newborn outcomes.

We found no positive impact of RBF on stillbirth despite the interventions targeting the quality care of women both antenatally and during labour. In
Mozambique, Pakistan, and India, a large study also showed no impact on stillbirth of a very large community intervention [26]. These programme experiences illustrate how complex a challenge prevention of stillbirth is, as components addressing population-level risk factors and the fine detail of maternity care arrangements across the continuum and especially at the critical time of labour and delivery all need to converge in an effective manner. In some settings the approach has given positive results. In Rwanda where the "pay for performance" intervention, similar in concept to RBF, there was an increase in utilization and quality of maternal and child care services [27]. In Bangladesh, a pay for performance strategy in $\mathrm{MNH}$ improved the volume of services provided although it did not address the quality of care [28]. Generally with RBF, improvements have been observed in service utilization but impact on quality has been harder to demonstrate. A recent analysis of the Bangladesh Maternal Health Voucher Scheme indicates a positive impact on access to services especially for marginalized women and on the completeness of antenatal care [29, 30]. Such impact might be expected to feed through to a reduction in stillbirth risk but evidence for this remains elusive to date.

\section{Study strengths and limitations}

The use of cross-sectional data only allows associations to be established, but not causality. However, a strength of the study was the inclusion of a comparison group. The intervention sites and the comparison sites were at the same level in the health system at different locations.

The study results may not represent the whole population of Malawi because only selected district hospitals were considered, and data collection did not include health centres. This study used routinely collected gestation and birth weight data and we were not able to formally confirm clinical causes of stillbirth. We used the traditional clinical classification of stillbirth as 'fresh' or 'macerated' in order to enable generalizability to the routine service setting where these terms are in use: this is known to be imprecise and there may well have been miss-classification between these categories. However, the main findings would not have been affected by some misclassification.

\section{Conclusion and recommendations}

We were not able to show positive effects of RBF4MNH on stillbirth risk. These findings highlight the need to re-focus interventions onto quality of care and close gaps in program implementation of RBF that might be preventing attainment of potential gains with regard to stillbirth prevention, notably intrapartum care arrangements. We consider that fresh stillbirth is a useful marker for intrapartum care hence an intervention should focus on it as a key indicator. Large scale 
programmatic investment should be underpinned by rigorous implementation research.

Notwithstanding the limitations of clinical classification without formal perinatal audit, recording of fresh stillbirth and macerated stillbirth in the Health Management Information System (DHIS-2) would enable routine capture of data from the districts for monitoring, planning and implementation of programs targeting care before and during delivery.

\begin{abstract}
Abbreviations
COMREC: College of Medicine Research and Ethics Committee; DHIS: District Health Management Information System; DHMT: District Health Management Team; ENAP: Every Newborn Action Plan; FANC: Focused Antenatal Care; FSB: Fresh stillbirth; MDHS: Malawi Demographic and Health Survey; $\mathrm{MoH}$ : Ministry of Health; MNH: Maternal and Newborn Health; MSB: Macerated stillbirth; PBF: Performance Based Finance; RHD: Reproductive Health Directorate.; SB: Stillbirth; QECH: Queen Elizabeth Central Hospital; RBF4MNH: Result Based Finance for Maternal and Newborn Health
\end{abstract}

\section{Acknowledgements}

Special thanks to the Directors of Health and Social Services in all the districts where the study was conducted for allowing access to the data and also to the midwives and data clerks for support in data collection. Statistical support from Evance Misomali is gratefully acknowledged.

\section{Authors' contributions}

RM undertook a literature search to find gaps in the area of interest, designed the study, conducted the field work, undertook analyses, and prepared the manuscript. WS provided supervision and scientific support throughout the process and edited the manuscript for content. Both authors approved the final version.

\section{Funding}

This project did not have any funding.

Availability of data and materials

Data will be available from the authors upon request made.

\section{Declarations}

\section{Ethics approval and consent to participate}

The College of Medicine Research Ethics Committee (COMREC) approved the study. This is a review board of the University of Malawi, College of medicine. Since de-identified secondary data was used, the need for participant consent was waived by the College of Medicine Research Ethics Committee. Permissions to access clinical data were sought from the district health offices.

\section{Consent for publication}

Not applicable.

\section{Competing interests}

The authors have no competing interests to declare.

\section{Author details}

${ }^{1}$ College of Medicine, The University of Malawi, Private Bag 360, Blantyre, Malawi. ${ }^{2}$ Center for Reproductive health, College of Medicine, The University of Malawi, Private Bag 360, Blantyre, Malawi.

Received: 16 September 2020 Accepted: 10 May 2021

Published online: 05 June 2021

\section{References}

1. Blencowe H, Cousens S, Jassir FB, Say L, Chou D, Mathers C, et al. National, regional, and worldwide estimates of stillbirth rates in 2015, with trends from 2000: a systematic analysis. Lancet Glob Health. 2016;4(2):e98-e108. https://doi.org/10.1016/S2214-109X(15)00275-2.
2. Lawn JE, Yakoob M, Haws RA, Soomro T, Darmstadt GL, Bhutta ZA. 3.2 million stillbirths: epidemiology and overview of the evidence review. BMC Pregnancy Childbirth. 2009;9(Suppl 1):S2.

3. The Ministry of Health in Malawi; Save the Children Malawi and UNICEF. Every newborn action plan: an action plan to end preventable neonatal deaths in Malawi. 2015.

4. McClure EM, Saleem S, Goudar SS, Moore JL, Garces A, Esamai F, et al. Stillbirth rates in low-middle income countries 2010-2013: a populationbased, multi-country study from the global network. Reprod Health. 2015; 12(2):S7. https://doi.org/10.1186/1742-4755-12-S2-S7.

5. McClure EM, Saleem S, Pasha O, Goldenberg RL. Stillbirth in developing countries: a review of causes, risk factors and prevention strategies. J Matern Fetal Neonatal Med. 2009;22(3):183-90. https://doi.org/10.1080/14767050802 559129

6. United Nations Inter-agency Group for Child Mortality Estimation, You D, Hug L, Mishra A, Blencowe H, Moran A. A neglected tragedy: the global burden of stillbirths. 2020. Available from: https://data.unicef.org/wpcontent/uploads/2020/10/UN-IGME-2020-Stillbirth-Report-updated.pdf [cited 2021 Jan 25].

7. Metaferia AM, Muula AS. Stillbirths and hospital early neonatal deaths at queen Elizabeth central hospital, Blantyre-Malawi. Int Arch Med. 2009;2(1):25. https://doi.org/10.1186/1755-7682-2-25.

8. Brenner $\mathrm{S}$, De Allegri M. Final results of the RBF4MNH impact evaluation prepared by the research team members of the University of Heidelberg and College of Medicine; 2016.

9. Kambala C, Lohmann J, Mazalale J, Brenner S, Sarker M, Muula AS, et al. Perceptions of quality across the maternal care continuum in the context of a health financing intervention: Evidence from a mixed methods study in rural Malawi. BMC Health Serv Res. 2017;17(1). Available from: http://bmchea Ithservres.biomedcentral.com/articles/10.1186/s12913-017-2329-6 [cited 2018 Sep 17].

10. Brenner CS, de Allegri M, Kambala C, Lohmann J. Final Results of the RBF4MNH Impact Evaluation; 2016. p. 1-111.

11. De Allegri M, Chase RP, Lohmann J, Schoeps A, Muula AS, Brenner S. Effect of results-based financing on facility-based maternal mortality at birth: an interrupted time-series analysis with independent controls in Malawi. BMJ Glob Health. 2019;4(3):e001184. https://doi.org/10.1136/bmjgh-2018-001184.

12. Bonfrer I, Soeters R, Van de Poel E, Basenya O, Longin G, van de Looij F, et al. Introduction of performance-based financing in burundi was associated with improvements in care and quality. Health Aff. 2014. Available from: https:// pubmed.ncbi.nlm.nih.gov/25489036/ [cited 2020 Aug 25].

13. WHO. Stillbirths. WHO. Available from: http://www.who.int/maternal_child_a dolescent/epidemiology/stillbirth/en/. [cited 2019 Sep 4].

14. National Statistical Office (NSO) [Malawi] and ICF International. Malawi Demograph ic and Health Sur- vey 2015-2016: Key Indicators Report. Zomba and Rockville: NSO and ICF International; 2016.

15. Petross C, McMahon S, Lohmann J, Chase RP, Muula AS, De Allegri M. Intended and unintended effects: community perspectives on a performance-based financing programme in Malawi. BMJ Glob Health. 2020; 5(4):e001894. https://doi.org/10.1136/bmjgh-2019-001894.

16. Goldenberg RL, Mcclure EM, Bann CM. The relationship of intrapartum and antepartum stillbirth rates to measures of obstetric care in developed and developing countries. Acta Obstet Gynecol Scand. 2007:86(11):1303-9. https://doi.org/10.1080/00016340701644876.

17. Jammeh A, Vangen S, Sundby J. Stillbirths in Rural Hospitals in the Gambia: A Cross-Sectional Retrospective Study. Obstet Gynecol Int. 2010. Available from: https://www.hindawi.com/journals/ogi/2010/186867/ [cited 2020 Apr 27].

18. Di Mario S, Say L, Lincetto O. Risk factors for stillbirth in developing countries: a systematic review of the literature. Sex Transm Dis. 2007:34(7): S11-21. https://doi.org/10.1097/01.olq.0000258130.07476.e3.

19. Lawn JE, Blencowe H, Waiswa P, Amouzou A, Mathers C, Hogan D, et al. Stillbirths: rates, risk factors, and acceleration towards 2030. Lancet. 2016; 387(10018):587-603. https://doi.org/10.1016/S0140-6736(15)00837-5.

20. Mcclure. Stillbirth in developing countries. Int J Gynecol Obstet. 2006;94(2): 82-90 Available from: https://obgyn.onlinelibrary.wiley.com/doi/abs/10.101 6/j.ijgo.2006.03.023, Wiley Online Library, [cited 2019 Sep 1].

21. Olusanya BO, Solanke OA. Predictors of term stillbirths in an inner-city maternity hospital in Lagos, Nigeria. Acta Obstet Gynecol Scand. 2009; 88(11):1243-51. https://doi.org/10.3109/00016340903287474.

22. Bhutta ZA, Darmstadt GL, Haws RA, Yakoob M, Lawn JE. Delivering interventions to reduce the global burden of stillbirths: improving service 
supply and community demand. BMC Pregnancy Childbirth. 2009;9(Suppl 1):S7. https://doi.org/10.1186/1471-2393-9-S1-S7.

23. Yussif A-S, Lassey A, Ganyaglo GY, Kantelhardt EJ, Kielstein $\mathrm{H}$. The long-term effects of adolescent pregnancies in a community in Northern Ghana on subsequent pregnancies and births of the young mothers. Reprod Health. 2017;14(1):178. Available from: https://reproductive-health-journal. biomedcentral.com/articles/10.1186/s12978-017-0443-x, [cited 2020 Apr 27].

24. Ganchimeg T, Ota E, Morisaki N, Laopaiboon M, Lumbiganon P, Zhang J, et al. Pregnancy and childbirth outcomes among adolescent mothers: a World Health Organization multicountry study. BJOG Int J Obstet Gynaecol. 2014;121:40-8. https://doi.org/10.1111/1471-0528.12630.

25. Lawn JE, Gravett MG, Nunes TM, Rubens CE, Stanton C. Global report on preterm birth and stillbirth (1 of 7): definitions, description of the burden and opportunities to improve data. BMC Pregnancy Childbirth. 2010;10(1): S1. https://doi.org/10.1186/1471-2393-10-S1-S1.

26. von Dadelszen P, Bhutta ZA, Sharma S, Bone J, Singer J, Wong H, et al. The community-level interventions for pre-eclampsia (CLIP) cluster randomised trials in Mozambique, Pakistan, and India: an individual participant-level meta-analysis. Lancet. 2020;396(10250):553-63. https://doi.org/10.1016/S014 0-6736(20)31128-4

27. Basinga P, Gertler PJ, Binagwaho A, Soucat AL, Sturdy J, Vermeersch CM. Effect on maternal and child health services in Rwanda of payment to primary health-care providers for performance: an impact evaluation. Lancet. 2011; 377(9775):1421-8. https://doi.org/10.1016/50140-6736(11)60177-3.

28. Rahman L, Rob U, Mahmud R, Alim A, Hena IA, Talukder M, et al. A pay-forperformance innovation integrating the quantity and quality of care in maternal, newborn and child health services in Bangladesh. 2011.

29. Mahmood SS, Amos M, Hoque S, Mia MN, Chowdhury AH, Hanifi SMA, et al. Does healthcare voucher provision improve utilisation in the continuum of maternal care for poor pregnant women? Experience from Bangladesh. Glob Health Action. 2019;12(1):1701324. https://doi.org/10.1080/16549716.2 019.1701324.

30. Mia MN, Mahmood SS, labal M, Bhuiya A, Pallikadavath S, Stones W. The Bangladesh Maternal Health Voucher Scheme: impact on completeness of antenatal care provision. J Biosoc Sci. 2021:1-8. https://doi.org/10.1017/ S0021932020000784. Epub ahead of print.

\section{Publisher's Note}

Springer Nature remains neutral with regard to jurisdictional claims in published maps and institutional affiliations.

Ready to submit your research? Choose BMC and benefit from:

- fast, convenient online submission

- thorough peer review by experienced researchers in your field

- rapid publication on acceptance

- support for research data, including large and complex data types

- gold Open Access which fosters wider collaboration and increased citations

- maximum visibility for your research: over $100 \mathrm{M}$ website views per year

At $\mathrm{BMC}$, research is always in progress.

Learn more biomedcentral.com/submissions 